\title{
The Distribution of Lead Between Sea Salt, Dust, and Lead-Rich Aerosols in the Mid South Pacific Easterlies at American Samoa
}

\author{
Kevin J. R. Rosman, ' Clair C. Patterson,and Dorothy M. Settle \\ Division of Geological and Planetary Sciences, California Institute of Technology, Pasadena
}

\begin{abstract}
Aerosols in the South Pacific Easterlies have been sampled at American Samoa with a cascade impactor and analysed for $\mathrm{Pb}, \mathrm{Ba}, \mathrm{K}, \mathrm{Ca}, \mathrm{Sr}$, and $\mathrm{Rb}$ by isotope dilution mass spectrometry using ultraclean procedures. Some $84 \%$ of the $\mathrm{Pb}$ was found in fine $(\leq 0.5 \mu \mathrm{m})$ aerosols which were collected on the backup filter with an efficiency of only 33\%. Sea salt and eroded terrestrial material (dust) containing $6 \%$ and $<1 \%$ respectively, of the $\mathrm{Pb}$ (sea salt indexed by the metals $\mathrm{K}, \mathrm{Ca}, \mathrm{Sr}$, and $\mathrm{Rb}$ and dust indexed by Ba) were collected on early stages of the impactor, although $65 \%$ of the dust, because of its larger size, was lost to surfaces of the rain shelter before reaching the impactor. The remaining $10 \%$ of the $\mathrm{Pb}$ was associated with plant leaf waxes of continental origin which produced $\mathrm{Pb}$ and $\mathrm{Ba}$ peaks on stage $4(0.5 \mu \mathrm{m})$ of the impactor.
\end{abstract}

\section{INTRODUCTION}

Marine boundary layer air samples were collected with a cascade impactor at a remote site in the South Pacific easterlies. This experiment was part of the National Science Foundation SEAREX (Sea-Air Exchange) Program carried out at American Samoa in 1981. Descriptions of the program, site, and relation to other major wind systems are given by Duce et al. [1983] and Arimoto et al. [1987].

The aims of this study were: (1) to confirm the findings of previous work which indicate that sea salt and dust (eroded terrestrial material) are represented as micron-sized particles of similar size while the heavy metals are concentrated on submicron particles, (2) to ascertain the distribution of $\mathbf{P b}$ between these three components in marine air and to seek evidence of micron-sized particles of continental origin which could be associated with plant leaf wax particles, and (3) to determine the extent to which sea salt aerosols are enriched in $\mathrm{Pb}$ so that a reliable correction for recycled sea salt can be made in calculations of $\mathrm{Pb}$ input fluxes to the oceans.

\section{EXPERIMENT}

\section{Sampling Site}

The collection site was Cape Matatula $\left(14^{\circ} \mathrm{S}, 170^{\circ} \mathrm{W}\right)$ located on the northern tip of Tutuila Island in American Samoa. The sampling devices were mounted on top of a $18-\mathrm{m}$ tower, located on the edge of a sheer $30-\mathrm{m}$ cliff. The approaching air was monitored continuously by meteorological recording devices and the decision to collect samples was made manually. Only those air parcels believed not to be contaminated by local emissions of anthropogenic lead were accepted. Some of the constraint evaluation techniques have been described by Arimoto et al. [1987].

\section{Cascade Impactors}

A Sierra Instruments model 235 cascade impactor incorporating five collection stages and two backup filters was

\footnotetext{
${ }^{1}$ Now at School of Physics and Geosciences, Curtin University of Technology, Perth, Western Australia.

Copyright 1990 by the American Geophysical Union.

Paper number 89JD03430.

0148-0227/90/89JD-03430\$05.00
}

used for sample collection. The device was mounted inside a cube-shaped rain shelter, $1 \mathrm{~m}$ on an edge, made from polypropylene sheet. Strips of siding, extending down $15 \mathrm{~cm}$ outside the box around its perimeter, were attached around the perimeter of the flat, square roof of the shelter. The flat roof was separated from the inner walls of the box by a $2.5-\mathrm{cm}$ gap. The impactor was mounted inside this shelter, facing inward, on one wall and was connected via corrugated polyethylene hose through the shelter wall to a pump located at the base of the tower. Air was pumped through the impactor at a rate of approximately $1133 \mathrm{Lmin}^{-1}$ (40 standard cubic feet per minute). The flow rate was monitored regularly during each collection period with a manometer. A volume of $7900 \mathrm{~m}^{3}$ of air passed through the impactor at intermittent intervals between July 4 and 21,1981 . The equivalent aerodynamic diameter (spherical particle with density of $1 \mathrm{~g} \mathrm{~cm}^{-3}$ ) values for $50 \%$ collection efficiency were $7,3.0,1.5,1.0,0.5$, and $\leq 0.5 \mu \mathrm{m}$ for the five collection stages and the backup stages respectively. A second backup stage was included to guard against backstreaming of particles from the pump, although subsequent analysis of this filter demonstrated that this was not a problem. Aerosols were collected on Whatman 41 cellulose filter media at each stage.

\section{Preparation of Cascade Impactor for Sampling}

The cleaning and assembly of the impactor was done in the California Institute of Technology (CIT) Pb-free laboratory. The Whatman 41 filter media used on impactor stages was subjected to sequential leaching by dilute $\mathrm{HF}$, ultrapure $\mathrm{H}_{2} \mathrm{O}$, dilute $\mathrm{HCl}$, ultrapure $\mathrm{H}_{2} \mathrm{O}$. Components of the impactor were leached in dilute $\mathrm{HNO}_{3}$ and high-purity $\mathrm{H}_{2} \mathrm{O}$, and then dried at ambient temperature. Because of a logistical problem, cleaned cellulose backup filters supplied by the Center for Atmospheric Chemistry Studies, University of Rhode Island (URI), were substituted for CIT backup filters. The assembled impactor was hermetically sealed in polyethylene bags for transportation to Samoa. At the sampling site, clean laboratory techniques were employed to handle and install the device in the shelter. Following the sampling period, the impactor was again hermetically sealed in polyethylene for transport to the CIT laboratory. 


\section{Chemical Analysis of Filters}

Samples were analysed for $\mathrm{K}, \mathrm{Ca}, \mathrm{Rb}, \mathrm{Sr}, \mathrm{Ba}$, and $\mathrm{Pb}$ by isotope dilution mass spectrometry. The slotted filter media used as impactor surfaces on stages 1 to 5 consisted of nine $12.5 \mathrm{~cm} \times 1 \mathrm{~cm}$ strips of paper arranged in a rectangular grid. The strips were sequentially numbered starting at one outside edge of the grid and were individually removed for analysis. There was a tenth collection strip on the outside edge of the grids on stages $2,3,4$, and 5, but this was partly covered by the device itself and therefore was not analyzed. Some strips of the slotted filters were analyzed separately, while others were pooled and digested together. For instance, on stage 1 , strips $4,6,7$, and 8 were pooled while 2 , 3,5 , and 9 were analyzed separately. In stage 2 , strips $(2,3$, $8),(1,9)$ and $(4,5,6,7)$ were pooled and analyzed.

The backup filter consisted of a $25.4 \mathrm{~cm} \times 20.3 \mathrm{~cm}$ sheet which was torn into quarters for analysis with the aid of acid-cleaned stainless steel tweezers. A $1-\mathrm{cm}$ border on the backup filter was not analyzed because it was shielded by the gasket from exposure.

Each sample was digested with a $\mathrm{HNO}_{3} / \mathrm{HClO}_{4}$ mixture in a covered $10-\mathrm{mL}$ quartz beaker. The beaker was first preconditioned with a $\mathrm{HNO}_{3}(3 \mathrm{~mL}) / \mathrm{HClO}_{4}(0.3 \mathrm{~mL})$ mixture, which was discarded. Tracers enriched in ${ }^{41} \mathrm{~K},{ }^{42} \mathrm{Ca},{ }^{87} \mathrm{Rb}$, ${ }^{84} \mathrm{Sr},{ }^{136} \mathrm{Ba}$, and ${ }^{208} \mathrm{~Pb}$ were weighed into the beaker, then the sample was added. Five milliliters of concentrated $\mathrm{HNO}_{3}$ were added, and the beaker was covered and heated at low temperature for 1 hour. $\mathrm{A} \mathrm{HNO}_{3}(0.3 \mathrm{~mL}) / \mathrm{HClO}_{4}(0.2$ $\mathrm{mL}$ ) mixture was then added, and the sample was heated for a further $30 \mathrm{~min}$. Additional heat was provided for a further $15 \mathrm{~min}$, adding concentrated $\mathrm{HNO}_{3}$ as required to prevent the sample from evaporating to dryness. Eight milliliters of $\mathrm{HNO}_{3}$ was sufficient to dissolve up to four strips of the impactor filter. The final solution was taken to dryness with slight excess of $\mathrm{HNO}_{3}$, and the residue was redissolved in dilute $\mathrm{HNO}_{3}$. Ten percent of this solution was taken for analysis of $\mathrm{K}, \mathrm{Rb}, \mathrm{Ca}, \mathrm{Sr}$, and $\mathrm{Ba}$, and the remainder was analysed for $\mathrm{Pb} . \mathrm{Pb}$ was isolated by dithizone solvent extraction [Patterson and Settle, 1976] before isotopic analysis was made; however, isolation was not needed for the other elements.

\section{Blanks}

Lead. The residual blank in the filter paper media was the main source of $\mathrm{Pb}$ contamination in analytical measurement. This amounted to $0.018 \mathrm{ng} \mathrm{cm}^{-2}$ per strip for the slotted paper and $0.077 \mathrm{ng} \mathrm{cm}{ }^{-2}$ for the backup filter. The reason for the difference between the blanks may have been due to either the use of a different filter lot for the backup filter or a difference between cleaning procedures used on filter media in the CIT and URI laboratories. Reagents and laboratory ware contributed a further $0.25 \mathrm{ng}$ per analysis. The reagent blank was estimated from the quantity of each reagent used and its corresponding $\mathrm{Pb}$ concentration, while ware blanks were determined individually for each container. Small quantities of $\mathrm{Pb}$ present in the alkaline earth and alkali metal tracer solutions were also taken into account.

Barium. The total analytical blank for slotted paper media was typically about $0.5 \mathrm{ng}$, with most of it coming from the paper itself. The Ba blank in the backup filter was much higher and greatly exceeded any air sample Ba on the

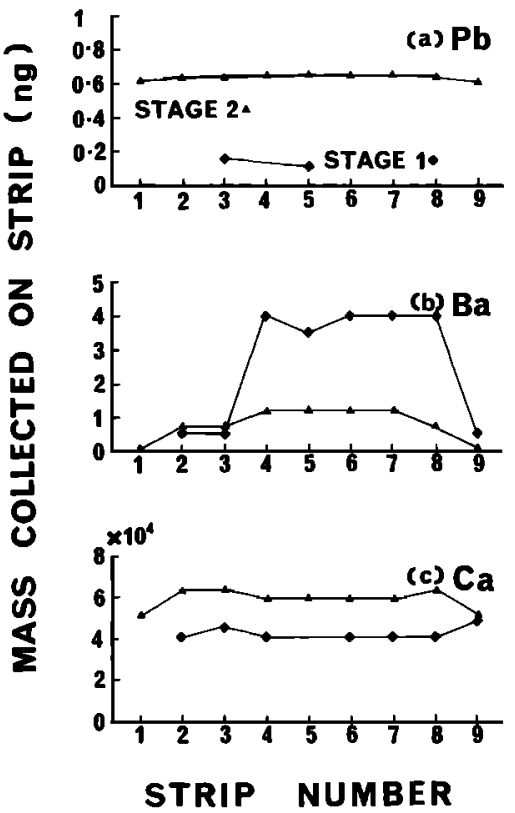

Fig. 1. Distributions of $(a) \mathrm{Pb},(b) \mathrm{Ba}$, and (c) $\mathrm{Ca}$ on strips of slotted paper impactor grids placed on the stages 1 and 2 of the cascade impactor.

filter. Large variations in this blank determined on different portions of unexposed filters made it impossible to determine air sample $\mathrm{Ba}$ on the backup filter.

Potassium, rubidium, calcium, and strontium. Because of the relatively large quantity of these metals present in the air samples, the blank corrections were generally less than a few percent of the sample.

\section{Isotope Dilution Mass Spectrometry (IDMS)}

Enriched isotopes were added to the sample prior to dissolution. After chemical treatment, metals were determined by IDMS using a single-focusing, sector field mass spectrometer fitted with a thermal ionisation source and an electron multiplier detector [Patterson and Settle, 1976]. For the purpose of this study the following isotope ratios were measured in the sample: ${ }^{208} \mathrm{~Pb} /{ }^{207} \mathrm{~Pb},{ }^{138} \mathrm{Ba} /{ }^{136} \mathrm{Ba},{ }^{88} \mathrm{Sr} /{ }^{84} \mathrm{Sr}$, ${ }^{40} \mathrm{Ca} /{ }^{42} \mathrm{Ca},{ }^{39} \mathrm{~K} /{ }^{41} \mathrm{~K}$, and ${ }^{85} \mathrm{Rb} /{ }^{87} \mathrm{Rb}$.

\section{RESULTS AND Discussion}

\section{Uniformity of Deposition}

Heterogeneity of deposition among the nine strips in each of two impactor stage grids is shown in Figures $1 a, 1 b$, and 1c. These show distributions of $\mathrm{Pb}, \mathrm{Ba}$, and $\mathrm{Ca}$ respectively, across grids of impactor stages 1 and 2 . Such data acquired for grids from other stages showed no definite trends and are not plotted.

It can be seen that $\mathrm{Ca}$ is uniformly distributed across both stages, while $\mathrm{Ba}$ is concentrated at the center and falls off at the edges. An asymmetry in the deposition is particularly noticeable on stage 1 and may reflect the orientation of the impactor in the shelter. The plateaulike shape of the deposition may be an artifact of pooling strips $4,6,7$, and 8 for analysis. A similar edge effect in deposition occurs on stage 2, although not as marked. $\mathrm{Pb}$ is uniformly distributed across stage 2 , but because only two stage 1 grids were successfully 
TABLE 1. Comparison of Performance of Cascade Impactor With Bulk Filter and Dry Deposition Plate

\begin{tabular}{|c|c|c|c|c|}
\hline Element & $\begin{array}{c}\text { Impactor*, } \\
\text { ng }\end{array}$ & $\begin{array}{c}\text { Bulk } \\
\text { Filter, } † \text { ng }\end{array}$ & $\begin{array}{c}\text { Bulk } \\
\text { Filter, } \dagger \mathrm{ng} \\
\mathbf{m}^{-3}\end{array}$ & $\begin{array}{c}\text { Dry } \\
\text { Deposition } \\
\text { Plate†, ng } \\
\mathrm{cm}^{-2} \mathrm{yr}^{-1}\end{array}$ \\
\hline $\mathbf{P b}$ & 76 & 174 & $2.2 \times 10^{-2}$ & 0.83 \\
\hline $\mathbf{K}$ & $1.1 \times 10^{6}$ & $1.1 \times 10^{6}$ & $1.4 \times 10^{2}$ & $\begin{array}{l}0.03 \\
\ldots\end{array}$ \\
\hline $\mathrm{Rb}$ & $3.3 \times 10^{2}$ & $3.8 \times 10^{2}$ & $4.8 \times 10^{-2}$ & $\ldots$ \\
\hline $\mathrm{Ca}$ & $1.2 \times 10^{6}$ & $1.1 \times 10^{6}$ & $1.4 \times 10^{2}$ & $3.4 \times 10^{4}$ \\
\hline $\mathrm{Sr}$ & $2.1 \times 10^{4}$ & $2.1 \times 10^{4}$ & 2.6 & $6.5 \times 10^{2}$ \\
\hline $\mathrm{Ba}$ & 40 & $1.1 \times 10^{2}$ & $1.4 \times 10^{-2}$ & 0.81 \\
\hline
\end{tabular}

*Mass of metal collected on all stages including backup filter.

$\dagger$ Patterson and Settle [1984].

analyzed, the deposition pattern could not be determined. These results indicate that all strips should be analyzed to ensure an accurate estimate of the quantity deposited on each stage. This is especially true for those chemical elements which are concentrated in larger particles and hence collect mainly on the first stage.

\section{Collection Efficiency of Impactor for $\mathrm{Pb}$.}

Data from a low-velocity bulk air filter sample and from a dry deposition plate sample, collected simultaneously with the impactor sample, are compared with the impactor data in Table 1. Details of techniques used for collection and analyses of the former samples are given by Settle and Patterson [1982], while results are given by Patterson and Settle [1984].

The field-measured volume of air pumped through the impactor required correction. Corrections on the fieldmeasured volume were determined by comparing total masses of metals collected by the high-velocity impactor with total masses of metals collected by the low-velocity bulk air filter. $\mathrm{Ca}, \mathrm{Sr}, \mathrm{K}$, and $\mathrm{Rb}$, residing on large particles, were collected with high efficiency by both devices so that differences would indicate error in volume measurement. Different values for the volume of the low velocity bulk filter sample, determined by three independent methods (integrated rotimeter flows, hot-wire conductivity flow meter, and integrated bellows gas meter), differed by less than $10 \%$. The mean value for this volume was used as a standard to determine, from the above metal concentrations in bulk air, that the corrected volume of the impactor sample was 7900 $\mathrm{m}^{3}$.

This volume, combined with the total mass of $\mathrm{Pb}$ collected on all stages and the backup filter of the impactor, can yield a concentration of $0.96 \times 10^{-2} \mathrm{ng} / \mathrm{m}^{3}$. This value represents $44 \%$ of the $2.2 \times 10^{-2} \mathrm{ng} / \mathrm{m}^{3}$ measured in the sample collected by the low-velocity bulk air filter. The loss of $\mathrm{Pb}$ in the impactor was probably associated with $\leq 0.5-\mu \mathrm{m}$ particles passing through the backup filter. The low collection efficiency for fine particles pumped at high velocities through Whatman 41 filter media is a recognized problem [Lodge, 1986]. Table 2 shows that $48 \mathrm{ng}$ of $\mathrm{Pb}$ were collected on the backup filter. When this is corrected for loss taking this to have occurred at the backup filter, the value becomes $146 \mathrm{ng}$ $\mathrm{Pb}$, yielding a total of $174 \mathrm{ng}$ of $\mathrm{Pb}$ which should have been collected by the impactor.

\section{Distribution of Pb Among Salt, Dust} and Fine Anthropogenic Aerosols

Table 2 and Figure $2 a$ shows quantities of $\mathrm{Pb}$ from $7900 \mathrm{~m}^{3}$ of air deposited on each of the five size-sorted impactor stages and the backup filter. Values corrected for errors in retention are also shown. Inhomogeneities in deposition were also considered in arriving at these values. These data indicate that $84 \%$ of total $\mathrm{Pb}$ in mid South Pacific easterlies air resides in anthropogenic fine particles of $\leq 0.5 \mu \mathrm{m}$ diameter.

Since most of the soil dust and sea salt aerosols in this marine air had diameters greater than $1.5 \mu \mathrm{m}$, they were

TABLE 2. Distribution of Metals on Cascade Impactor

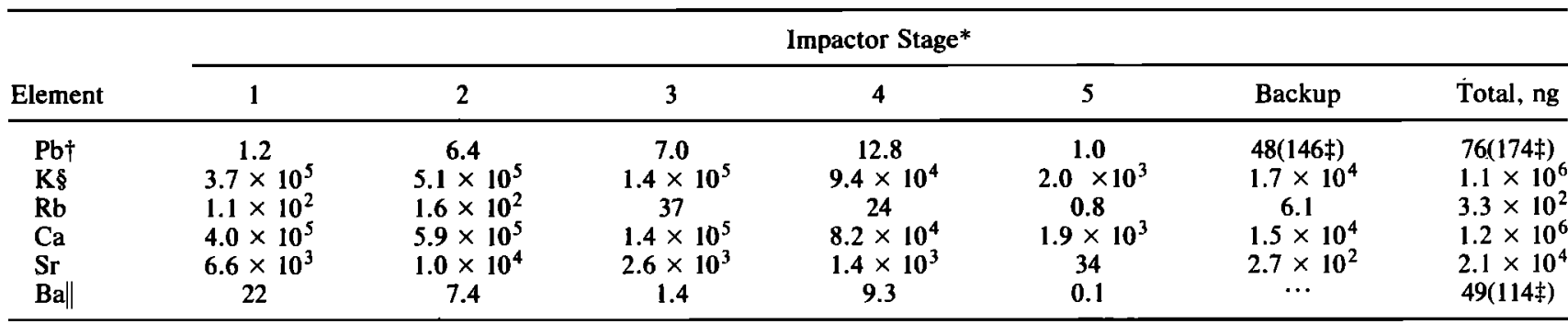

*Mass deposited is given in nanograms.

$\dagger$ Amounts are uncertain by \pm 0.5 to $0.8 \mathrm{ng}$.

$\ddagger$ Corrected for loss by comparison with bulk filter data (see text).

$\S$ Amounts of $\mathrm{K}, \mathrm{Rb}, \mathrm{Ca}$, and $\mathrm{Sr}$ are uncertain by $\pm 5 \%$.

|Amounts are uncertain by \pm 0.3 to $1.1 \mathrm{ng}$. 

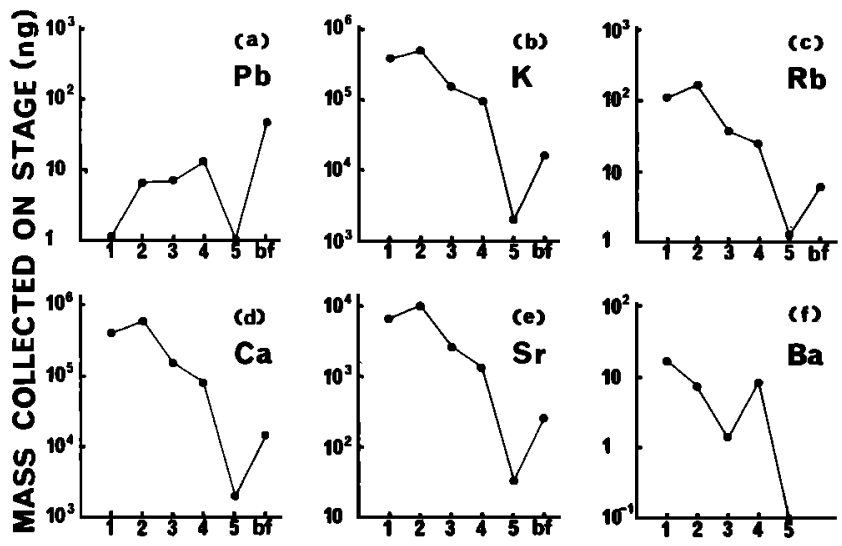

CASCADE IMPACTOR

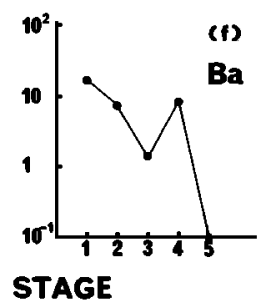

Fig. 2. Mass size distributions for (a) $\mathrm{Pb},(b) \mathrm{K},(c) \mathrm{Rb},(d) \mathrm{Ca}$, (e) $\mathrm{Sr}$, and $(f) \mathrm{Ba}$ collected on the cascade impactor at American Samoa. Mass median diameter cutoffs for the stages are as follows: $1,7 \mu \mathrm{m} ; 2,3 \mu \mathrm{m} ; 3,1.5 \mu \mathrm{m} ; 4,1 \mu \mathrm{m} ; 5,0.5 \mu \mathrm{m}$; and backup filter, $\leq 0.5 \mu \mathrm{m}$.

collected on the first two stages of the impactor. Bounce-off smearing of intermediate-sized particles occurs from the dry filter paper impactor collecting surface used in this experiment [Reischl and Berkeley, 1979]. About half the $\mathrm{Pb}$ on the third stage can probably be assigned to sea salt. Dust, indexed from barium [Patterson and Settle, 1987], amounts to less than $0.1 \%$ of the total mass on the first three stages of the impactor and contributes approximately $1 \mathrm{ng}$ of $\mathrm{Pb}$. The rest of the $\mathrm{Pb}$ on these three stages can be attributed to sea salt. Reference to data in Table 2 therefore indicates that about $6 \%$ of total $\mathrm{Pb}$ in mid South Pacific easterlies resides in sea salts. Since the particle enrichment mechanism for $\mathrm{Pb}$ in sea spray salt has been shown by isotopic tracers to operate on industrial lead-rich fine particles [Seattle and Patterson, 1982; Patterson and Settle, 1987], most of the $\mathrm{Pb}$ in sea salt aerosols is industrial.

These data also indicate that about $10 \%$ of total $\mathrm{Pb}$ in this air resides in particles whose diameters range from about 1 to $2 \mu \mathrm{m}$. This $\mathrm{Pb}$ may originate from lead-rich organic particles derived from leaf epidermal waxes, because these same size particles collected from marine air at other remote sites have been shown to be composed of such organic compounds (E. Peltzer et al., Woods Hole Oceanographic Institutions, unpublished data, 1984). It is known that a major fraction of the first stage of eolian deposition of industrial $\mathrm{Pb}$ on the continents outside of urban regions is located on plant foliage [Patterson and Settle, 1987], so it would be expected that aerosols derived from leaf surface waxes would be lead-rich. The leaf wax particles are larger than the lead-rich particles deposited on their surfaces. There is a dust maximum in this same size range, as indexed from $\mathrm{Ba}$ and shown in Figure $2 f$. This is in accord with expectations that similar deposition mechanisms operate for both dust and lead-rich particles in the favorable size range, which would result in collection by both momentum and diffusion impact mechanisms on leaf surfaces in continental regions.

Nearly $100 \%$ of the $\mathrm{Pb}$ assigned by the above considerations to anthropogenic fines $(84 \%)$, sea salts $(6 \%)$, leaf waxes $(10 \%)$, and soil dusts $(<1 \%)$ is industrial.

\section{Enrichment of $\mathrm{Pb}$ in Sea Salt Aerosols}

An enrichment factor for $\mathrm{Pb}$ in recycled sea salt aerosols,

[aerosol $(\mathrm{Pb} / \mathrm{salt})] /[$ seawater $(\mathrm{Pb} /$ salt $)]$

is required to calculate the net eolian input flux of $\mathrm{Pb}$ to the oceans. This factor is combined with the concentration of salt in rain to correct for recycled sea spray $\mathrm{Pb}$ it contains. The impactor data obtained here provides a measurement of the enrichment factor for $\mathrm{Pb}$ in sea salt aerosols that are airborne and have not gravitationally settled. Virtually all such sea salt was collected on the first two stages of the impactor (Figures $2 b$ and $2 d$ ), but data from stage 1 cannot be used because of the small amount of $\mathrm{Pb}$ and the excessive error caused by the $\mathrm{Pb}$ blank. The enrichment factor for $\mathrm{Pb}$ determined from stage 2 is $\mathbf{1 1 0 0}$. The corresponding value determined from deposition plate data for the same time and place (Table 1) is $\mathbf{2 4 0 0}$. These two types of measurement involve the selection of different sized particles. Approximate agreement between the two values suggests that dilution of microlayer film by different amounts of seawater in aerosols of varying sizes is not a major factor in determining the range of values observed for the enrichment factor. Patterson and Settle [1987] have used a global value of 5000 for the $\mathrm{Pb}$ enrichment factor, determined from both dry deposition plate data at a number of locations and from this impactor data. These data included values ranging from 1100 to 26,000 .

\section{Dust, Indexed From Ba}

The impactor should have collected a total of $114 \mathrm{ng}$ of $\mathrm{Ba}$, computed from the amount of $\mathrm{Ba}$ collected by the lowvelocity bulk filter, but it collected only $35 \%$ of this quantity. Ba can be used as an index for soil dust with an accuracy comparable to that for an $\mathrm{Al}$ index [Patterson and Settle, 1987], and data in Table 2 and Figure $2 f$ show that more than half of the dust collected by the impactor was deposited on the first stage. The sharp cutoff between the stages 1 and 2 suggest that the dust particles were significantly larger than $7 \mu \mathrm{m}$. It appears that about $65 \%$ of the dust in the air was not passed through the impactor but probably collected on rain shelter surfaces before reaching it. The rain shelter for the low-velocity bulk filter was an open-ended, downwardfacing shield which provided an unobstructed pathway for aerosols to the filter. The pathway for aerosols to the high-velocity impactor involved two right-angled turns within a confined space, which probably sorted out much of the larger dust particles before they reached the impactor.

Acknowledgments. We thank our colleagues at the Graduate School of Oceanography at the University of Rhode Island for providing the impactor collection device and associated pumping equipment. This experiment was made possible by the cooperative effort of members of the interuniversity NSF SEAREX program, and their contributions made this experiment possible. We also thank members of the NOAA GMCC observatory at the American Samoa site for their generous assistance in field operations. This research was supported by NSF grants OCE 77-14520 and OCE 81-11893, A02. Division of Geological and Planetary Sciences, California Institute of Technology, contribution 4601.

\section{REFERENCES}

Arimoto, R., R. A. Duce, B. J. Ray, A. D. Hewitt, and J. Williams, Trace elements in the atmosphere of American Samoa: Concen- 
trations and deposition to the tropical South Pacific, J. Geophys. Res., 92, 8465-8479, 1987.

Duce, R. A., R. Arimoto, B. J. Ray, C. K. Unni, and P. J. Harder, Atmospheric trace elements at Enewetak Atoll, 1, Concentrations, sources and temporal variability, J. Geophys. Res., 88, $5321-5342,1983$.

Lodge, J. P., Use of Whatman 41 filter papers in particle sampling, Atmos. Environ., 20, 1657, 1986.

Patterson, C. C., and D. M. Settle, The reduction of order of magnitude errors in lead analyses of biological materials and natural waters by evaluation and controlling the extent and sources of industrial lead contamination introduced during sample collecting, handling, and analysis, in Accuracy in Trace Analysis: Sampling, Sampling Handing, and Analysis, edited by P. La Fleur, NBS U.S. Spec. Publ., 422, 321-351, 1976.

Patterson, C. C., and D. M. Settle, Magnitudes of eolian lead fluxes to the ocean at American Samoa, SEAREX Newsl. 7, 13-18, Univ. of R. I., Kingston, 1984.

Patterson, C. C., and D. M. Settle, Review of data on eolian fluxes of industrial and natural lead to the lands and seas in remote regions on a global scale, Mar. Chem., 22, 137-162, 1987.

Reischl, G., and W. J. Berkeley, The collection efficiency of impaction surfaces: A new impaction surface, Staub Reinhalt Lift , 38, 55, 1979.

Settle, D. M., and C. C. Patterson, Magnitudes and sources of precipitation and dry deposition fluxes of industrial and natural leads to the North Pacific at Enewetak, J. Geophys. Res., 87, $8857-8869,1982$.

C. C. Patterson and D. M. Settle, Division of Geological and Planetary Sciences, California Institute of Technology, 4800 Oak Grove Drive, Pasadena, CA 91125.

K. J. R. Rosman, School of Physics and Geosciences, Curtin University of Technology, GPO Box U 1987, Perth 6001, Western Australia.

(Received August 2, 1988; revised November 3, 1989; accepted November 7, 1989.) 